\section{ON THE NATURE OF INHIBITION, AND THE ACTION OF DRUGS UPON IT ${ }^{1}$}

III.

THE first important contribution to our knowledge of inhibitory centres in the brain and spinal cord was that of Setchenow. He found that when the cerebral lobes in a frog were removed, voluntary motion was abolished, but reflex action became somewhat more marked. On removal of the optic lobes, the reflex action became very greatly increased, and if, instead of removing them they were stimulated either chemically by a grain of salt laid upon them, or electrically, reflex action in the limbs was greatly retarded or completely abolished.

These experiments were repeated by Herzen, who, like Setchenow, considered that there was no inhibitory mechanism in the spinal cord itself, but disbelieved also in inhibitory centres in the brain. He explained the depression of reflex which occurred on irritation of the optic lobes by supposing that any intense nervous irritation, no matter whether it was central or peripheral, caused great depression of reflex action both when the brain was intact and when it was divided, as in Setchenow's experiments. Setchenow again repeated his experiments, and came to the conclusion that it was uncertain whether the inhibitory mechanism could be excited reflexly from the periphery. He made, also, a sharp distinction between tactile and painful impressions upon the skin. For tactile impressions he considered that there was no inhibitory mechanism in the brain. Further investigations still, showed that both chemical and electrical irritation would excite the inhibitory apparatus, and he, therefore, considered that both excito-motor and depressor fibres were present in the same nerve-trunk. ${ }^{2}$ Goltz found, in opposition to Setchenow, that there was an inhibitory apparatus for tactile reflexes also in the frog's brain, but this he found in the cerebral lobes, ${ }^{3}$ while Setchenow denied any inhibitory function to that part of the brain altogether.

He found also, however, like Herzen, that complete abolition of reflex action could be produced by powerful irritation of any peripheral sensory nerve, and considers that the irritation is conveyed to the reflex centre, and diminishes or destroys its excitability for the original stimulus, without supposing that there is any special inhibitory centre.

Lewisson found that by powerfully compressing the neck, or by squeezing the feet, or some other part of the body of a frog, or by irritation of the cutaneous or muscular nerves, or by electricity, the reflex excitability could be much depressed. He found, however, that unless the irritation was strong it produced stimulation both of the reflex and motor centres of the brain instead of depression. ${ }^{4}$

The general conclusion to which all these experiments, as well as those of Fick, ${ }^{5}$ Freusberg, and others lead is, either that the nerves contain both excito-motor and reflex depressing fibres, or that excitement and depression can be produced by the same nerves under different conditions.

Freusberg, ${ }^{6}$ who discusses the question of inbibition in an able and thorough manner, comes to the conclusion that all instances of inhibition including the different effects of weak and powerful stimuli applied to the same nerve, and also the inhibitory effects of stimulation of different nerves on each other, are not due to specific

I Continued from p. 439 .

${ }^{2}$ Uber die elektr. und chem. Reizung der sensiblen Ruckenmarksnerven des Frosches, 1868 . Quoted by v. Boetticher, op. cit. p. 6.

Goltz, op. cit. p. 42

4 Lewisson, "Ueber Hemmung der Thätigkeit der motor. Nervencentren durch Reizung sensibler Nerven," Archiv. f. Anatomie u. Physiol. 1860. 5 Fick, Verhandlungen der physikalisch medicinischen Gesellschaft $z$ Wurzburg, April $23,1870$.

6 Freusberg, "Ueber die Erregung u. Hemmung d. Thätigkeit d. nervösen Centralorgane," Pflüger's Archiv. x. x74. inhibitory centres, but to a remarkable property of the central nervous system, which does not allow of its different parts being simultaneously set in action by different causes. This conclusion, although it may be nearer the truth than the hypothesis of separate inhibitory centres, is not satisfactory, for it still leaves us in the dark regarding the way in which the central nervous system comes to possess the remarkable properties which he attributes to it.

Setchenow explains the increased rapidity of reflex action after section of the cord below the medulla oblongata, by supposing that there are two paths along which the stimulus usually passes, from the sensory to the motor tracts. The one goes directly across, and this is the path taken after section. The other goes up to the medulla, and then down the cord. This is the path taken under ordinary conditions; but besides the apparent unlikelihood that the stimulus should take this longer path under normal conditions, an objection has been raised to it by Cyon which seems fatal.

Cyon finds that when the so-called inbibitory centres are stimulated, although reflex contraction of the leg is apparently delayed for a long time, this delay is to a great extent only apparent and not real. ${ }^{1}$

It is true that the vigorous contraction of the muscles which suffices to raise the limb is much delayed, but a contraction of these muscles commences at very nearly the same time that it would do if the inhibitory apparatus were not stimulated. This shortening of the muscle goes on very gradually for a considerable time, and then culminates in a sudden vigorous contraction, the total height of which is greater than that of the contraction which would have occurred without irritation of the inhibitory centres. It is very difficult to explain this result on the ordinary hypothesis, but easy enough on that of interference. According to it we suppose that a stimulus applied to the foot has been transmitted as usual from the sensory to the motor cells of the cord, and thence to the muscles, so as to initiate contraction in them. This stimulus would correspond to the first half wave in the diagram (Fig. 2). The subsequent waves of stimulation which would have proceeded from the motor ganglia have been interfered with by the stimuli passing down from the socalled inhibitory centre, but their times being not arranged so that each wave from the brain should fall half a wavelength behind that in the cord, the stimuli at length cease to interfere, and the contraction, which has gone on gradually increasing as the interference diminishes, at last finishes abruptly.

The part of the brain which ought to correspond in higher animals to the optic lobes in frogs is the corpora quadrigemina, but irritation of these parts has not been found to have any marked inhibitory action upon reflexes in the limbs. ${ }^{2}$

Irritation of the frontal lobes in puppies has, however, been found by Simonoff ${ }^{3}$ to exercise an inhibitory action; but, according to Ferrier, abolition of the frontal lobes in monkeys does not produce any very obvious effect upon the animal. ${ }^{4}$ We know that by an effort of the will, we are able either to increase or diminish reflex action, and it might appear probable that irritation of the motor tracts in the cerebrum might have an inhibitory action on reflexes. Irritation of the cerebral motor areas has not been found to exercise any definite inhibitory action upon reflexes, but on the other hand Exner ${ }^{5}$ has found, if a stimulus be applied simultaneously to a motor area in the brain and to an extremity, the two stimuli aid one another, and produce a greater effect than they would separately. As irritation

x Cyon, Ludwig's Festgabe, p. clxviii.

2 Setschenow Physiologische Studien über die Hemmungs-mechanismen für die Reflexthätigkeit des Rückenmarkes im Gehirn des Frosches, p. 3 (Berlin: Hirschwald, 1863 ).

3 Simonoff, Arch. f. Atrat. u. Phys. p. 545, 1866.

4 Ferrier, Functions of the Brain, p. 230 (London, 1876).

5 Exner, Pflüger's Archiv. xxviii. 487. 
of the cerebral motor areas, therefore, does not exercise a definite inhibitory action upon reflexes, but does under certain conditions markedly increase them, one might expect that their removal would diminish reflex action. Such a diminution actually occurs when they are destroyed in disease, but when the brain is removed layer by layer in operations upon animals, it is usually found that the reflex increases in proportion to the quantity removed. When the whole brain is removed, the reflex action is greater than when it is present, and as the cord is cut away layer by layer, the excitability of the seg nent below appears to be increased; each layer, as has already been mentioned, appearing to have an inhibitory influence on the one below it. But this is not always the case, because we sometimes find on removal of the various parts of the brain or of the spinal cord that the section completely abolishes reflex action for the time.

We are accustomed frequently to cloak our ignorance of the true cause of this abolition by saying it is due to the shock of operation or something of that sort; but looking the facts fairly in the face, we find that sometimes removal of the upper part of the brain or spinal cord causes increase and sometimes diminution of reflex-action in the parts below. At present we have no satisfactory explanation of this phenomenon, but if we suppose in the one case the nervous matter to have been removed in such a way as to cause an interference of the stimuli passing along from cell to cell, and in the other to cause a coincidence, we can readily understand the occurrence of the two different conditions. Moreover, we have said several times, that inhibition or stimulation are only relative conditions depending on the length of path along which the stimulus has to travel, and the rapidity with which it travels. The length of path remaining the same, the occurrence of stimulation or inhibition depends upon the rapidity of passage of the stimulus. The same length of path which is just suffi cient to throw successive impulses of a slowly travelling stimulation half a wave-length behind the other, and produce inhibition, may be just sufficient to throw the vibrations of another more rapidly transmitted stimulus a whole wave-length behind, and produce increased instead of diminished action.

If the hypothesis that inhibition is produced by interference be true, we shall be able to test it by seeing whether stimulation of certain nerves which, under the ordinary conditions produce inhibition, do so when the rate of transmission of nervous impulses is altered. The length of path being the same, if we alter the rapidity of transmission it is probable that as the rapidity diminishes, the inhibition will be converted into stimulation, again possibly passing into inhibition, according as the stimuli, which we normally suppose to be half a wavelength behind each other, are thrown a whole wavelength, or a wave-length and a half behind each other. At a certain period, also, the waves of stimulation will be neither a whole nor a half wave-length behind each other, but the fraction of a wave-length. In such cases we shall neither have constant coincidence, nor constant interference, but we shall have rhythmical coincidence and rhythmical interference, the result of which will be that we shall neither get constant motion, nor constant arrest of motion, but alternate motion and rest. In other words we shall neither have complete rest nor tonic contractions, but intermittent or clonic contractions. Now this condition is exactly what we do find when one sciatic of a frog is irritated twenty-four hours after it has been exposed. We have already mentioned that when irritated immediately after exposure it had the effect simply of abolishing reflex action in the other leg; but the same irritation applied in the same manner after many hours, instead of causing arrest in the other leg, causes clonic convulsions. ${ }^{1}$

This occurrence is very hard to explain on the ordinary

I Nothnagel, Centralblatt f. d. med. Wiss. March 28, r869, p. 2x. hypothesis of separate and distinct inhibitory centres, but it agrees perfectly with the hypothesis that inhibition and stimulation are merely relative conditions.

I have repeated Nothnagel's experiments, but I have not got the same results. Irritation of the sciatic nerve indeed caused a certain diminution in reflex at first, but irritation after twenty-four hours caused no clonic convulsions, it merely appeared somewhat to stimulate reflex action in the other leg. The reason of this discrepancy in our results is probably that the temperature was different in the two cases. Nothnagel's results were published in March, and his experiments were probably performed during cold weather, while mine were done during very mild weather. If the effects which he noticed were due to definite inhibitory centres in the spinal cord similar experiments should have had similar results in his hands and mine If on the other hand the effects simply depend on the rate of the transmission of nervous impulses it is easy to understand why the results were different in the two cases.

There are also certain pbenomena connected with the action of drugs on the spinal cord which are almost inexplicable on the ordinary hypothesis, but which are readily explained on that of interference. Thus belladonna when given to frogs causes gradually increasing weakness of respiration and movement, until at length voluntary and respiratory movements are entirely abolished, and the afferent and efferent nerves are greatly weakened. Later still, both afferent and efferent nerves are completely paralysed, and the only sign of vitality is an occasional and hardly perceptible beat of the heart and retention of irritability in the striated mussles. The animal appears to be dead, and was believed to be dead, until Fraser made the observation that if allowed to remain in this condition for four or five days, the apparent death passed away and was succeeded by a state of spinal excitement. The forearms passed from a state of complete flaccidity to one of rigid tonic contraction. The respiratory movements reappeared; the cardiac action became stronger, and the posterior extremities extended. In this condition a touch upon the skin caused violent tetanus usually opisthotonic, lasting from two to ten seconds, and succeeded by a series of clonic spasms. A little later still the convulsions change their character and become emprosthotonic. These symptoms are due to the action of the poison upon the spinal cord itself, for they continue independently in the parts connected with each segment of the cord when it has been divided.

This action may be imitated by a combination of a paralysing and exciting agent such as strychnia and methyl-strychnia. Fraser concludes that the effects of large doses of atropia just described are due to a combined stimulant and paralysing action of the substance on the cord, and that the difference in the relations of these effects to each other, which are seen in different species of animals, may be explained by this combination acting on special varieties of organisation.

\section{T. LAUDER BRUNTON}

(To be continued.)

\section{NOTES}

THE Queen has signified her intention of opening the International Fisheries Exhibition, at South Kensington, on Saturday, May I2.

BARON NORDENSKJöld writes to us that he has definitely settled to start for the interior from Auleitsivik Fjord on the west coast, and then, in September, to go round Cape Farewell along the east coast to the $n$ rrth.

A MosT interesting letter has been received at Kew Observatory from Mr. Coo'ssley, of Cajt. Dawson's expedition to Fort Rae. They arrived on August 30, started the meteorologica 